\section{What is already known on this topic}

In perimenopausal women the prevalence of urinary incontinence is about $10-15 \%$

Several factors are responsible for lower urinary tract symptoms

Little is known about the prevalence and clinical course of lower urinary tract symptoms, and knowledge about the clinical course is an important consideration in treatment

\section{What this study adds}

During the clinical course of lower urinary tract symptoms women experience more or fewer symptoms

An awareness of why these changes occur can help in decisions about treatment
3 Milsom I, Ekelund P, Molander U, Arvidsson L, Areskoug B. The influence of age, parity, oral contraception, hysterectomy and menopause on the prevalence of urinary incontinence in women. J Urol 1993;149: 1459-62.

4 Yarnell JW, Voyle GJ. The prevalence and severity of urinary incontinence in women. J Epidemiol Community Health 1981;35:71-4.

5 Samuelsson E, Victor A, Tibblin G. A population study of urinary incontinence and nocturia among women aged 20-59 years. Prevalence, well-being and wish for treatment. Acta Obstet Gynecol Scand 1997;76: 74-80.

6 Sommer P, Bauer T, Nielsen KK, Kristensen ES, Hermann GG, Steven K, et al. Voiding patterns and prevalence of incontinence in women. A questionnaire survey. Br J Urol 1990;66:12-5.

7 Møller LA, Lose G, Jørgensen T. The prevalence and bothersomeness of lower urinary tract symptoms in women 40-60 years of age. Acta Obstet Gynecol Scand 2000;79:298-305.

8 Campbell AJ, Reinken J, McCosh L. Incontinence in the elderly: prevalence and prognosis. Age Ageing 1985;14:65-70.

9 Herzog AR, Diokno AC, Brown MB, Normolle DP, Brock BM. Two-year incidence, remission, and change patterns of urinary incontinence in noninstitutionalized older adults. J Gerontol 1990;45:M67-74.

10 Burgio KL, Matthews KA, Engel BT. Prevalence, incidence and correlates of urinary incontinence in healthy, middle-aged women. I Urol 1991:146:1255-9.

11 Nygaard IE, Lemke JH. Urinary incontinence in rural older women: prevalence, incidence and remission. J Am Geriatr Soc 1996;44:1049-54.

12 Holtedahl K, Verelst M, Schiefloe A. A population based, randomized, controlled trial of conservative treatment for urinary incontinence in women. Acta Obstet Gynecol Scand 1998;77:671-7.

ence more or fewer symptoms. Specific reasons for remission and rates of remission in women seeking treatment remain to be elucidated.

This study was supported with grants from Coloplast; Pharmacia and Upjohn; the research foundation of Bornholm, Frederiksborg, Roskilde, Storstrøms, and Vestsjællands counties; the Rudolph Foundation; the Kleins Foundation; the research foundation of Copenhagen, Faroe Island, and Greenland; the foundation of Niels and Desirees Yde; and the county hospital of Nykøbing Falster.

Contributors: LAM performed the study, corresponded with the patients, analysed the data, and wrote the paper. GL had the original idea for the study and helped with the study design, data analysis, and writing the paper. TJ helped with the study design, data analysis, and writing the paper. All authors will act as guarantors for the paper.

Conflict of interest: None declared.

1 Thomas TM, Plymat KR, Blannin J, Meade TW. Prevalence of urinary incontinence. BMJ 1980;281:1243-5.

2 Elving LB, Foldspang A, Lam GW, Mommsen S. Descriptive epidemiology of urinary incontinence in 3,100 women age 30-59. Scand J Urol Nephrol Suppl 1989;125:37-43.
13 Nygaard IE, Thompson FL, Svengalis SL, Albright JP. Urinary incontinence in elite nulliparous athletes. Obstet Gynecol 1994;84:183-7.

14 Bump RC, McClish DK. Cigarette smoking and urinary incontinence in women. Am J Obstet Gynecol 1992;167:1213-8.

15 Jozwik M. Stress urinary incontinence in women-an overuse syndrome. Med Hypotheses 1993;40:381-2.

16 Mommsen S, Foldspang A. Body mass index and adult female urinary incontinence. World J Urol 1994;12:319-22.

17 Diokno AC, Brock BM, Herzog AR, Bromberg J. Medical correlates of urinary incontinence in the elderly. Urology 1990;36:129-38.

18 Creighton SM, Stanton SL. Caffeine: does it affect your bladder? Br J Urol 1990;66:613-4.

19 Abrams P, Blaivas JG, Stanton SL, Andersen JT. The standardisation and terminology of lower urinary tract function. $\mathrm{Br} J$ Obstet Gynaecol 1990;97:1-16.

20 Bernstein I, Sejr T, Able I, Andersen JT, Fischer-Rasmussen W, Klarskov P, et al. Assessment of lower urinary tract symptoms in women by a self-administered questionnaire: test-retest reliability. Int Urogynecol J Pelvic Floor Dysfunct 1996;7:37-47.

21 Jackson S, Donovan J, Brookes S, Eckford S, Swithinbank L, Abrams P. The Bristol female lower urinary tract symptoms questionnaire: development and psychometric testing. Br J Urol 1996;77:805-12

22 Holtedahl K, Hunskaar S. Prevalence, 1-year incidence and factors associated with urinary incontinence: a population based study of women 50-74 years of age in primary care. Maturitas 1998;28:205-11

(Accepted 2 February 2000)

\title{
Association between psychosocial work characteristics and health functioning in American women: prospective study
}

Yawen Cheng, Ichiro Kawachi, Eugenie H Coakley, Joel Schwartz, Graham Colditz

Department of

Health and Social

Behavior, Harvard

School of Public

Health, Boston,

MA 02115, USA

Yawen Cheng

research fellow

Harvard Center for Society and Health, Harvard School of Public Health

Ichiro Kawachi

director

continued over

BMJ 2000;320:1432-6

\begin{abstract}
Objective To examine prospectively the relation between psychosocial work characteristics and changes in health related quality of life over four years in a cohort of working women in the United States.

Design Longitudinal cohort study.

Setting United States.
\end{abstract}

Participants 21290 female registered nurses who completed the Karasek's job content questionnaire and a modified version of the short form 36 questionnaire (SF-36) as used for a survey of health status by the medical outcomes study.

Main outcome measures Seven dimensions of health status: physical functioning, role limitations due to physical health problems, bodily pain, vitality, social functioning, role limitations due to emotional problems, and mental health.

Results Examined separately low job control, high job demands, and low work related social support were associated with poor health status at baseline as well as greater functional declines over the four year follow up period. Examined in combination, women with low job control, high job demands, and low work related social support ("iso-strain" jobs) had the greatest functional declines. These associations could not be explained by age, body mass index, comorbid disease status, alcohol consumption, smoking status, education level, exercise level, employment status, marital status, or presence of a confidant.

Conclusions Adverse psychosocial work conditions are important predictors of poor functional status and its decline over time. 


\section{Introduction}

The job strain model as conceptualised by Karasek and Theorell postulates that a combination of high psychological demands with low control at work leads to mental and physical illnesses. ${ }^{1-3}$ Previous studies have linked job strain to hypertension, cardiovascular disease, cigarette smoking, psychosomatic symptoms, depression, and adverse birth outcomes. ${ }^{13-9}$

With few exceptions, ${ }^{11}{ }^{11}$ previous studies have assessed job strain on only one occasion. Although older workers have been reported to be more susceptible to job strain, it is unclear whether age is a proxy for cumulative exposure. ${ }^{412}$ Moreover, most studies have focused on conventional measures of mortality and morbidity. The impact of job strain on health functioning and sense of wellbeing have been reported in only a few recent studies. ${ }^{13-15}$

We studied the cumulative effects of job strain on health status in a large cohort of women in the United States, with repeated measures of job characteristics. We hypothesised that job strain not only predicts poor health status but also accelerates functional decline over time.

\section{Participants and methods}

\section{Study population}

Participants were from the nurses' health study, an ongoing cohort of female registered nurses in the United States. This study began in 1976 when 121700 women (98\% white) aged 30-55 years completed a mailed questionnaire regarding risk factors for major disease. Follow up questionnaires are sent biennially to update information on exposure and the incidence of new diseases.

The assessment of job characteristics and general health status began in 1992, when 75434 women (69\% response rate) returned a questionnaire that included the Karasek's job content questionnaire and the short form 36 health questionnaire (SF-36). Of these women, 34558 were in the paid work force and were free of coronary heart disease, stroke, and cancer. Of these, 31330 returned the follow up questionnaire in 1996. We excluded 1540 women who developed coronary heart disease, cancer, or stroke between 1992 and 1996. We further excluded 6814 women who retired and 1686 women with missing data on either any item in the job content questionnaire or more than half the items in a subscale of the SF-36. This left 21290 women available for our study, $16287(76.5 \%)$ of whom were working as nurses in 1996.

\section{Psychosocial job characteristics}

Psychosocial job conditions were measured with the job content questionnaire. ${ }^{16}$ The job demands subscale is the sum of five items inquiring about excessive work, conflicting demands, insufficient time to work, fast pace, and working hard. The job control scale is the sum of two subscales: skill discretion as measured by six items (learning new things on the job, ability to develop new skills, job requiring skill, task variety, work not repetitious, job requiring creativity) and decision authority as measured by three items (freedom to make decisions, choice about how to perform work, having a lot of say in the job). The work related social support scale is the sum of two subscales: support from coworkers (four items) and supervisors (four). For each item the respondents could choose from one of four responses ranging from strongly disagree to strongly agree.

\section{Health status}

Health status was assessed by a modified version of the SF-36 as used for a survey of health status by the medical outcomes study. ${ }^{17}$ We examined seven of the eight dimensions of SF-36: physical functioning, measuring the ability to perform a variety of daily activities and tasks that require physical effort (10 items); role limitations due to physical health problems (four); freedom from bodily pain (two); vitality, measuring the perceived level of energy and fatigue (four); social functioning (two); role limitations due to emotional problems (three); and mental health, assessing both positive and negative emotional states (five). All participants responded to at least half the items in a scale. An average score was used to estimate the missing values (less than 1\%), following procedures described in the SF-36 manual. ${ }^{17}$ All scales were transformed to range between 0 (worst health) and 100 (best health).

\section{Potential confounding factors}

Data on several biological and behavioural factors were obtained by questionnaire: age (years), body mass index $\left(\mathrm{kg} / \mathrm{m}^{2}\right)$, smoking status (never, former, and current smoker), alcohol intake ( $\mathrm{g} /$ day), presence of comorbid conditions including diabetes, hypertension, hypercholesterolaemia, osteoarthritis, and rheumatoid arthritis (yes or no), employment status (part time or full time), presence of a confidant (yes or no), marital status (married or not married), educational attainment (advanced or graduate degree, registered nurse or bachelor degree), and exercise level (metabolic equivalent of work hours per week).

\section{Statistical analysis}

We examined the effects of psychosocial job characteristics averaged between 1992 and 1996 on the SF-36 measured in 1996. Additionally, we examined change in SF-36 scores over a four year period as an outcome. As expected, changes in SF-36 scores were negatively correlated with the baseline scores. ${ }^{18}{ }^{19}$ We adjusted for baseline SF-36 scores measured in 1992, with the intercept terms constrained to be zero.

Multivariate linear regression models were used to control for potential confounding factors. To aid interpretability, the job control and job demands subscales were divided into thirds, whereas work related social support was split into two groups on the median. For continuous covariables, generalised additive models were applied to examine non-parametrically the shapes of their associations with SF-36 outcomes, ${ }^{20}$ and any necessary transformation was carried out. Age was treated as a continuous variable, and an additional age squared term was included to accommodate polynomial associations between age and most of the SF-36 outcomes. All analyses were conducted with the SAS program.
Department of Nutrition, Harvard School of Public Health

Eugenie H Coakley research fellow

Department of Environmental Health, Harvard School of Public Health

Joel Schwartz associate professor

Channing

Laboratory, Department of Medicine, Brigham and Women's

Hospital, Boston MA 02115, USA Graham Colditz professor

Correspondence to: I Kawachi Ichiro.Kawachi@ channing.

harvard.edu 
Table 1 Personal characteristics, job content, and health status scores of participants and women excluded from study. Values are numbers (percentages) unless stated otherwise

\begin{tabular}{|c|c|c|}
\hline Variable measured in 1992 & $\begin{array}{l}\text { Participants } \\
(\mathrm{n}=21290)\end{array}$ & $\begin{array}{l}\text { Excluded women } \\
(\mathrm{n}=13 \mathrm{268})\end{array}$ \\
\hline Mean (SD) age (years) & $54.0(5.3)$ & $57.8(5.9)$ \\
\hline Mean (SD) body mass index $\left(\mathrm{kg} / \mathrm{m}^{2}\right)$ & $26.0(5.0)^{\star}$ & $26.4(5.1) \dagger$ \\
\hline \multicolumn{3}{|l|}{ Education level: } \\
\hline $\begin{array}{l}\text { Registered nurse or bachelor } \\
\text { degree }\end{array}$ & 18139 (85.2) & $11776(88.8)$ \\
\hline Graduate degree & 3067 (14.4) & $1425(10.7)$ \\
\hline Data missing & $84(0.4)$ & $67(0.5)$ \\
\hline \multicolumn{3}{|l|}{ Marital status: } \\
\hline Married & $17403(81.7)$ & $10636(80.2)$ \\
\hline Not married & $3863(18.2)$ & $2618(19.7)$ \\
\hline Data missing & $24(0.1)$ & $14(0.1)$ \\
\hline \multicolumn{3}{|l|}{ Smoking status: } \\
\hline Never & 9567 (44.9) & $5667(42.7)$ \\
\hline Former & $8698(40.9)$ & $5456(41.1)$ \\
\hline Current & $2986(14.0)$ & $2123(16.0)$ \\
\hline Data missing & $39(0.2)$ & $22(0.2)$ \\
\hline \multicolumn{3}{|l|}{ Chronic illness: } \\
\hline Yes & $11482(53.9)$ & $8554(64.5)$ \\
\hline No & $9808(46.1)$ & $4714(35.5)$ \\
\hline \multicolumn{3}{|l|}{ Employment status: } \\
\hline Full time & $14350(67.4)$ & $7421(55.9)$ \\
\hline Part time & $6816(32.0)$ & $5721(43.1)$ \\
\hline Data missing & $124(0.6)$ & $126(1.0)$ \\
\hline \multicolumn{3}{|l|}{ Mean (SD) job content (1992): } \\
\hline Job control & $73.1(10.8)$ & $71.4(10.6)$ \\
\hline Job demands & $31.6(6.1)$ & $30.8(6.1)$ \\
\hline Work related social support & $24.0(3.7) \ddagger$ & $23.9(3.6) \S$ \\
\hline \multicolumn{3}{|l|}{ Mean (SD) SF-36 health status (1992)ף: } \\
\hline Physical functioning & $90.3(13.7)$ & $86.9(16.6)$ \\
\hline Role physical & $82.3(30.2)$ & $77.5(33.9)$ \\
\hline Bodily pain & $76.9(18.5)$ & $74.7(20.0)$ \\
\hline Vitality & $64.0(17.8)$ & $62.9(18.1)$ \\
\hline Social functioning & $90.0(17.1)$ & $88.5(18.9)$ \\
\hline Role emotional & $84.7(27.8)$ & $83.4(28.9)$ \\
\hline Mental health & $76.1(14.1)$ & $76.0(14.3)$ \\
\hline $\begin{array}{l}\text { *20 } 119 . \\
\dagger 12364 . \\
+18473 . \\
\text { \$11 } 141 . \\
\text { IHigher scores indicate better health }\end{array}$ & & \\
\hline
\end{tabular}

\section{Results}

Table 1 compares the personal characteristics, job content scores, and SF-36 scores for 21290 participants in 1992 with those of 13268 participants included in a previous cross sectional study ${ }^{15}$ but excluded from our study. Compared with women who were excluded, the participants were younger, better educated, less likely to have a chronic disease, and more likely to be a full time worker. The participants also reported higher levels of job demands (31.6 versus 30.8) and job control (73.1 versus 71.4). The mental health subscales were comparable between the two groups, although in terms of physical health subscales, women included in our study seemed to be healthier.

During the four year period the overall job demands of the group decreased slightly (31.6 in 1992 to 31.3 in 1996) whereas job control increased slightly (73.1 to 73.7). Job content assessed at two points of time showed a moderate degree of stability, with correlation coefficients for job control, job demands, and social support of $0.60,0.54$, and 0.41 respectively. The demands and control scores were not correlated with each other (correlation coefficients less than 0.10). Work related social support was positively correlated with job control $(\mathrm{r}=0.20$ to 0.37$)$ but negatively correlated with job demand $(\mathrm{r}=-0.10$ to -0.22$)$.

Having a body mass index greater than $29 \mathrm{~kg} / \mathrm{m}^{2}$, not being married (including never married, separated, divorced, and widowed), having a lower level of educational attainment, and being a current smoker were all associated with lower SF-36 scores in all the seven subscales.

The follow up SF-36 scores assessed in 1996 were regressed on job content scores averaged between 1992 and 1996 (table 2). In all the models, significantly better health status was found in women with higher levels of job control, lower levels of job demands, and higher levels of work related social support after adjustment for potential confounders. The effect sizes were greater when the average scores of job strain over the four year period were used compared with either 1992 or 1996 job content scores alone.

The joint effects of job demands and control on SF-36 were next examined by including dummy variables made up of combinations of each subscale divided into thirds. Although results of only three subscales (physical functioning, vitality, and mental health) are shown in table 3 owing to space limitations, all the seven subscales were analysed, and the results showed a similar pattern. Women in the highest third of job demands and the lowest third of job control (reference group, "high strain" job) had the worst health status, whereas those in jobs with the highest control and

Table 2 Multivariate regression coefficients (95\% confidence intervals) ${ }^{\star}$ of SF-36 scores in 1996 by categories of averaged scores of job content from 1992 and 1996

\begin{tabular}{|c|c|c|c|c|c|c|c|}
\hline & Physical functioning & Role physical & Bodily pain & Vitality & Social functioning & Role emotional & Mental health \\
\hline \multicolumn{8}{|l|}{ Job control } \\
\hline Intermediate $v$ low & 0.45 (-0.13 to 1.02$)$ & 2.73 (1.64 to 3.82 ) & $1.08(0.44$ to 1.72$)$ & 3.26 (2.65 to 3.88$)$ & $1.00(0.45$ to 1.55$)$ & 3.15 (2.27 to 4.03$)$ & 2.61 (2.13 to 3.09 ) \\
\hline High $v$ low & 1.46 (0.85 to 2.06$)$ & 6.43 (5.27 to 7.58$)$ & 2.76 (2.09 to 3.44$)$ & $7.16(6.51$ to 7.81$)$ & 2.83 (2.26 to 3.41$)$ & 5.97 (5.04 to 6.90$)$ & 5.16 (4.66 to 5.67$)$ \\
\hline \multicolumn{8}{|l|}{ Job demands } \\
\hline Intermediate $v$ high & $0.73(0.15$ to 1.30$)$ & 3.22 (2.12 to 4.62 ) & 2.01 (1.37 to 2.66 ) & 2.68 (2.06 to 3.30$)$ & 2.37 (1.81 to 2.92$)$ & 3.66 (2.77 to 4.55$)$ & 2.67 (2.18 to 3.15$)$ \\
\hline Low $v$ high & 0.98 (0.34 to 1.61) & 4.22 (3.01 to 5.43 ) & 2.88 (2.18 to 3.59 ) & 4.21 (3.53 to 4.89 ) & 3.02 (2.42 to 3.63 ) & 5.34 (4.36 to 6.31$)$ & 4.40 (3.87 to 4.93$)$ \\
\hline \multicolumn{8}{|l|}{ Social support } \\
\hline High $v$ low & 1.66 (1.12 to 2.20$)$ & 6.29 (5.25 to 7.32$)$ & 3.14 (2.54 to 3.74$)$ & 5.36 (4.77 to 5.94$)$ & 3.21 (2.68 to 3.73 ) & 5.94 (5.11 to 6.78$)$ & $4.46(4.00$ to 4.91$)$ \\
\hline$\%$ effect size (high $v$ low) $\dagger$ & 12.1 & 20.8 & 17.0 & 30.1 & 18.8 & 21.4 & 31.6 \\
\hline
\end{tabular}

*Adjusted for age, age ${ }^{2}$, body mass index, alcohol consumption, smoking status, exercise level, chronic disease status, part time or full time status, presence of a confidant, marital status, education level, job insecurity, and physical effort at work.

†Calculated by dividing difference between adjusted means of two groups by standard deviation for that subscale. 
lowest demands ("low strain" job) had the best health status. When analyses were stratified by level of work related social support, women reporting lower social support had lower scores in all the SF-36 subscales compared with women reporting higher social support.

All effect estimates changed little when analyses were restricted to women who remained in nursing (data not shown). The SF-36 scales assessed at two points of time were moderately correlated, with correlation coefficients ranging from 0.32 for the role emotional subscale to 0.63 for the vitality subscale. Over the four years of follow up, scores in the physical health domain deteriorated, whereas vitality and mental health status improved (table 4 ). Women reporting low job control, high job demand, and low work related social support had greater declines in the physical health subscales and less improvement in mental health subscales. The patterns remained after adjustment of other covariables.

\section{Discussion}

Women in jobs with high demands, low control, and low social support ("iso-strain" jobs) showed the greatest declines in health status. Our findings supported our hypotheses that cumulative measures of job demands and control provided a more stable assessment of the associations than concurrent measures. The effects of job strain were independent of a variety of potential confounders.

A comparison between participants and those who were excluded from analysis because of major illness or retirement suggested a healthy worker effect. Healthier employees are more likely to remain working whereas those with health problems may shift to jobs with lower strain or quit work altogether. If participants shifted to jobs with lower strain because of their health problems there would be a selection bias leading to an underestimation of the effects of job strain on health.

There is some debate about whether the job demand dimension predicts health. A review by Schnall et $\mathrm{al}^{4}$ found significant associations between job control and cardiovascular outcomes in 17 of 25 studies (68\%), whereas associations with job demands were found in only eight of 23 studies $(35 \%)$. Several recent substudies from the Whitehall II study of British
Table 3 Multivariate regression coefficients (95\% confidence intervals) ${ }^{*}$ of SF-36 scores for physical functioning, vitality, and mental health in 1996 by categories of averaged scores for job content from 1992 and 1996

\begin{tabular}{|c|c|c|c|}
\hline \multirow{2}{*}{$\begin{array}{l}\text { Job control in } \\
\text { category }\end{array}$} & \multicolumn{3}{|c|}{ Job demands } \\
\hline & Low & Intermediate & High \\
\hline \multicolumn{4}{|c|}{ Physical functioning } \\
\hline High & 2.63 (1.53 to 3.73 ) & 2.48 (1.43 to 3.53$)$ & 1.82 (0.81 to 2.82$)$ \\
\hline Intermediate & 1.85 (0.79 to 2.92$)$ & 1.32 (0.33 to 2.32$)$ & $0.54(-0.51$ to 1.58$)$ \\
\hline Low & $1.23(0.21$ to 2.26$)$ & 1.09 (0.09 to 2.09$)$ & 0 (reference) \\
\hline \multicolumn{4}{|l|}{ Vitality } \\
\hline High & 12.51 (11.34 to 13.68$)$ & 10.93 (9.81 to 12.05$)$ & 8.82 (7.75 to 9.89$)$ \\
\hline Intermediate & 8.73 (7.60 to 9.86$)$ & 7.25 (6.19 to 8.31$)$ & 3.74 (2.63 to 4.86$)$ \\
\hline Low & 5.84 (4.75 to 6.93$)$ & 3.90 (2.83 to 4.96$)$ & 0 (reference) \\
\hline \multicolumn{4}{|l|}{ Mental health } \\
\hline High & 10.52 (9.60 to 11.43$)$ & 8.81 (7.94 to 9.86$)$ & 6.38 (5.55 to 7.21$)$ \\
\hline Intermediate & 7.69 (6.81 to 8.57$)$ & 6.35 (5.52 to 7.17$)$ & 3.13 (2.26 to 3.99$)$ \\
\hline Low & 5.78 (4.94 to 6.63$)$ & 3.36 (2.53 to 4.20$)$ & 0 (reference) \\
\hline
\end{tabular}

*Adjusted for age, age ${ }^{2}$, body mass index, alcohol consumption, smoking status, exercise level, chronic disease status, part time or full time status, presence of a confidant, marital status, education level, job insecurity, and physical effort at work.

civil servants also showed that poor health was associated with lower job control but not with high job demands. ${ }^{11} 1421$ Questions have been raised regarding colinearity between work characteristics and socioeconomic status. Does the better predictive power of job control reflect a closer correlation to socioeconomic position than job demands? In the Whitehall II study, high job demands and high job control were highly correlated-both were more prevalent in higher employment grades. ${ }^{22}$ In the nurses' health study, the low correlation between job control and job demands meant more power to examine their independent effects on health.

A previous report from this cohort showed that social networks were positively associated with mental functioning. ${ }^{23}$ Our study extends those findings by indicating the deleterious effects of low social support in the workplace. This finding is consistent with other studies. ${ }^{72} 24$

An important issue concerns the validity of self reported data. Since both the exposure and outcomes were assessed by self report, there was potential for bias by people reporting in a negative manner on both. People with negative affectivity may perceive their environment more negatively, creating an artificial correlation between work environment and health outcomes. Reserve causation is another major issue in

Table 4 Multivariate changes (95\% confidence intervals) ${ }^{*}$ in SF-36 scores between 1992 and 1996 in relation to average scores of job characteristics from 1992 and 1996

\begin{tabular}{|c|c|c|c|c|c|c|c|}
\hline & Physical functioning & Role physical & Bodily pain & Vitality & Social functioning & Role emotional & Mental health \\
\hline \multicolumn{8}{|l|}{ Job control } \\
\hline Low & $-3.76(-4.95$ to -2.57$)$ & $-3.43(-5.86$ to -1.00$)$ & $-0.06(-1.42$ to 1.30$)$ & $-0.07(-1.23$ to 1.10$)$ & 2.22 (1.01 to 3.44$)$ & $0.64(-1.35$ to 2.62$)$ & 2.13 (1.19 to 3.08$)$ \\
\hline Intermediate & $-3.78(-5.00$ to -2.55$)$ & $-1.83(-4.32$ to 0.67$)$ & $0.46(-0.93$ to 1.86$)$ & $1.12(-0.07$ to 2.32$)$ & 2.69 (1.44 to 3.93 ) & 2.85 (0.82 to 4.88$)$ & 3.21 (2.24 to 4.18$)$ \\
\hline \multicolumn{8}{|l|}{ Job demands } \\
\hline High & $-4.13(-5.37$ to -2.88$)$ & $-4.67(-7.21$ to -2.12$)$ & $-0.89(-2.32$ to 0.53$)$ & $-0.43(-1.65$ to 0.80$)$ & $1.06(-0.21$ to 2.34$)$ & $-0.99(-3.07$ to 1.09$)$ & $1.30(0.30$ to 2.29$)$ \\
\hline Intermediate & $-3.73(-4.95$ to -2.51$)$ & $-2.44(-4.93$ to 0.05$)$ & $0.20(-1.20$ to 1.59$)$ & $0.48(-0.72$ to 1.67$)$ & 2.68 (1.44 to 3.93 ) & $1.62(-0.41$ to 3.64$)$ & 2.56 (1.59 to 3.53 ) \\
\hline \multicolumn{8}{|c|}{ Social support } \\
\hline Low & $-3.65(-5.01$ to -2.28$)$ & $-4.52(-7.31$ to -1.73$)$ & $-1.07(-2.62$ to 0.47$)$ & $-0.66(-2.00$ to 0.68$)$ & $1.36(-0.06$ to 2.77$)$ & $-0.03(-2.31$ to 2.26$)$ & 1.57 (0.48 to 2.67$)$ \\
\hline High & $-2.78(-4.15$ to -1.40$)$ & $0.06(-2.75$ to 2.86$)$ & $0.81(-0.74$ to 2.36$)$ & $1.76(0.41$ to 3.10$)$ & 3.56 (2.14 to 4.98$)$ & 4.30 (2.01 to 6.59$)$ & 3.69 (2.59 to 4.79$)$ \\
\hline
\end{tabular}

Model intercepts are constrained to be zero-that is, departure from zero (no change between 1992 and 1996) are tested.

${ }^{*}$ Adjusted for age, age ${ }^{2}$, body mass index, alcohol consumption, smoking status, exercise level, chronic disease status, part time or full time status, presence of confidant, marital status, education level, job insecurity, and physical effort at work. 


\section{What is already known on this topic}

Stressful job conditions, characterised by low control, high demands, and low social support, increase the risk of cardiovascular disease

Previous cross sectional studies suggested that job strain is associated with low functional health status

\section{What this study adds}

A prospective study of 21290 female nurses in the United States found that low control in their jobs predicted significant declines in physical function and mental health

The effects of job strain on functioning were independent of socioeconomic status, baseline functioning, and other confounders

The declines in health functioning associated with job strain were as large as those associated with smoking and sedentary lifestyles

research into job stress. ${ }^{25}$ It has been argued that unhealthy or less socially competent people may drift to worse jobs with lower levels of control over decision making. Both these sources of bias may partly account for the observed associations in our study. Objective measures of job content and information on personality are needed to clarify this issue.

Currently, most solutions proposed to reduce job stress, such as relaxation therapy and modification of lifestyle, target individuals rather than their social environment and tend to deal with symptoms instead of causes. If the psychosocial work environment contributes to the quality of life of the workforce-as suggested by our study-hospitals and medical practices will need to focus their strategies for health promotion on the redesign of jobs.

We thank the members of the nurses' health study for their continuing participation and support

Contributors: YC participated in the study design, carried out the data analyses, and took primary responsibility for writing the paper. IK formulated the primary study hypotheses, designed the study, and contributed to the interpretation of the findings and the preparation of the manuscript; he will act as guarantor for the paper. EHC provided statistical and programming advice, documented the data, and participated in the preparation of the manuscript. JS provided statistical advice and helped in interpretation of the data and editing the manuscript. GC is the principal investigator of the study. He helped develop the primary study hypotheses, took part in the study design, and contributed to the interpretation of the data and editing of the manuscript.

Funding: This research was funded by a grant from the National Institute of Aging Research (R01-AG-12806). The nurses' health study is funded by a grant from the National Institutes of Health (R01-CA-40356). IK was supported by the MacArthur Foundation Network on Socioeconomic Status and Health and a career development award from the National Institutes of Health (HL03453).

Competing interests: None declared.

1 Karasek R, Theorell T. Healthy work-stress, productivity, and the reconstruction of working life. New York: Basic Books, 1990

2 Karasek R, Baker D, Marxer F, Ahlbom A, Theorell T. Job decision latitude, job demands, and cardiovascular disease: a prospective study of Swedish men. Am J Public Health 1981;71:694-705.

3 Karasek RA, Theorell T, Schwartz JE, Schnall PL, Pieper CF, Michela JL. Job characteristics in relation to the prevalence of myocardial infarction in the US health examination survey (HES) and the health and nutrition examination survey (HANES). Am J Public Health 1988;78:910-8.

4 Schnall PL, Landsbergis PA, Baker D. Job strain and cardiovascular disease. Ann Rev Public Health 1994;15:381-411.

5 Schnall PL, Schwartz JE, Landsbergis PA, Warren K, Pickering TG. Relation between job strain, alcohol, and ambulatory blood pressure Hypertension 1992;19:488-94.

6 Hellerstedt WL, Jeffery RW. The association of job strain and health behaviours in men and women. Int J Epidemiol 1997;26:575-83.

7 Landsbergis PA, Schnall PL, Deitz D, Friedman R, Pickering T. The patterning of psychological attributes and distress by "job strain" and social support in a sample of working men. J Behav Med 1992;15:379-405.

8 Homer C, James S, Siegel E. Work-related psychosocial stress and risk of preterm, low birth weight delivery. Am J Public Health 1990;135:173-7.

9 Fenster L, Schaefer C, Mathur A, Hiatt R, Pieper C, Hubbard A, et al. Psychologic stress in the workplace and spontaneous abortion. $\mathrm{Am} \mathrm{J}$ Epidemiol 1995;142:1176-83.

10 Theorell T, Perski A, Akerstedt T, Sigala F, Ahlberg-Hulten G, Svensson J, et al. Changes in job strain in relation to changes in physiological state. A longitudinal study. Scand J Work Environ Health 1988;14:189-96.

11 Bosma H, Marmot MG, Hemingway H, Nicholson AC, Brunner E, Stansfeld SA, et al. Low job control and risk of coronary heart disease in Whitehall II (prospective cohort) study. BMJ 1997:314:558-65.

12 Johnson J, Hall E. Job strain, work place social support, and cardiovascular disease: a cross-sectional study of a random sample of the Swedish working population. Am J Public Health 1988;78:1336-42.

13 Lerner D, Levine S, Malspeis S, D'Agostino R. Job strain and health-related quality of life in a national sample. Am J Public Health $1994 ; 84: 1580-5$.

14 Stansfeld S, Bosma H, Hemingway H, Marmot M. Psychosocial work characteristics and social support as predictors of SF-36 health functioning: the Whitehall II study. Psychosom Med 1998;60:247-55.

15 Amick BC 3rd, Kawachi I, Coakley EH, Lerner D, Levine S, Colditz GA. Relationship of job strain and iso-strain to health status in a cohort of women in the United States. Scand J Work Environ Health 1998;24:54-61.

16 Karasek R. Job content questionnaire and user's guide. Lowell, MA: Department of Work Environment, University of Massachusetts-Lowell, 1985.

17 Ware J, Snow K, Kosinski M, Gandek B. SF-36 health survey: manual and interpretation guide. Boston, MA: New England Medical Center, Health Institute, 1993

18 Rosner B. The analysis of longitudinal data in epidemiologic studies. $J$ Chronic Dis 1979;32:161-73.

19 Cain K, Kronmal R, Kosinski A. Analysing the relationship between changes in a risk factor and risk of disease. Stat Med 1992;11:783-97.

20 Hastie T, Tibshirani R. Generalized additive models. London: Chapman and Hall, 1990.

21 Marmot MG, Bosma H, Hemingway H, Brunner E, Stansfeld S. Contribution of job control and other risk factors to social variations in coronary heart disease incidence. Lancet 1997;350:235-9.

22 Marmot MG, Smith GD, Stansfeld S, Patel C, North F, Head J, et al. Health inequalities among British civil servants: the Whitehall II study. Lancet 1991:337:1387-93

23 Achat H, Kawachi I, Levine S, Berkey C, Coakley E, Colditz G. Social networks, stress and health-related quality of life. Qual Life Res 1998;7:735-50.

24 Johnson JV, Hall EM, Theorell T. Combined effects of job strain and social isolation on cardiovascular disease morbidity and mortality in a random sample of the Swedish male working population. Scand J Work Environ Health 1989;15:271-9.

25 Zapf D, Dormann C, Frese M. Longitudinal studies in organizational stress research: a review of the literature with reference to methodological issues.J Occup Health Psychol 1996;1:145-69.

(Accepted 7 February 2000)

\section{Corrections and clarifications}

Using thresholds based on risk of cardiovascular disease to target treatment for hypertension: modelling events averted and number treated

Confusion over denominators led to an error in this paper by Simon Baker and colleagues (11 March, pp 680-5). In table 1 the denominators for women receiving treatment should have been 322 (not 316) for those aged 35-49 years and 353 (not 300) for those aged 50-64.

Association between teenage pregnancy rates and the age and sex of general practitioners: cross sectional survey in Trent 1994-7

In this paper by Julia Hippisley-Cox and colleagues (25 March, pp 842-5) the fourth potential confounder in table 2 should have read "rural practice $v$ urban practice" (not urban practice $v$ rural practice) as teenage pregnancy rates were lower in rural areas. 